\title{
Produção de palha e forragem por espécies anuais e perenes em sucessão à soja
}

\author{
Luís Armando Zago Machado(1) e Paulo Giovani Gall de Assis ${ }^{(2)}$
}

(1)Embrapa Agropecuária Oeste, Caixa Postal 661, CEP 79804-970 Dourados, MS. E-mail: zago@cpao.embrapa.br (2)Fundação Vegetal, Caixa Postal 661, CEP 79804-970 Dourados, MS. E-mail: giovani@cpao.embrapa.br

Resumo - O objetivo deste trabalho foi avaliar a produção de palha e de forragem por forrageiras anuais e perenes implantadas em sucessão à cultura da soja, e seus efeitos sobre a produtividade de grãos da cultura no próximo cultivo. O delineamento experimental utilizado foi o de blocos ao acaso, com parcelas subdivididas (crescimento livre e sob cortes sucessivos), com quatro repetições. Foram avaliadas oito forrageiras em dois municípios de Mato Grosso do Sul. A produção de palha e forragem foi avaliada em 2005 e 2006, nas espécies Urochloa ruziziensis; $U$. decumbens; $U$. brizantha cv. Marandu e Xaraés; Panicum maximum cv. Tanzânia e Mombaça, P. maximum x P. infestans cv. Massai; Pennisetum americanum cv. BRS 1501; e Sorghum bicolor cv. Santa Elisa. As forrageiras foram semeadas mecanicamente após a colheita da soja, em 1/4/2005 e 24/3/2006, em São Gabriel do Oeste, e em 20/3/2005 e 13/3/2006, em Dourados. Sorgo, U. brizantha cv. Xaraés e $P$. maximum cv. Tanzânia apresentaram características como elevada produtividade, alta qualidade da forragem e facilidade de controle, favoráveis para produção tanto de forragem quanto de palha. Urochloa ruziziensis e $U$. decumbens apresentaram melhor desempenho para a produção de palha. O cultivo das espécies forrageiras em sucessão à soja não afeta a produtividade da cultura.

Termos para indexação: Panicum, Urochloa, integração lavoura-pecuária, milheto, plantas de cobertura, plantio direto.

\section{Straw and forage production of annual and perennial species in succession to soybean}

\begin{abstract}
The objective of this work was to evaluate forage and straw production, of annual and perennial forage implanted in succession to soybean, and their effects on crop grain yield in the following season. The experimental design was in randomized blocks with four replicates, in a split-plot arrangement (free growth and successive cuts). Eight forages were evaluated in two municipalities of the state of Mato Grosso do Sul, Brazil. Straw and forage production was evaluated in 2005 and 2006, in the following species: Urochloa ruziziensis, $U$. decumbens; $U$. brizantha cv. Marandu and Xaraés; Panicum maximum cv. Tanzânia and Mombaça, P. maximum x P. infestans cv. Massai, Pennisetum americanum cv. BRS 1501, and Sorghum bicolor cv. Santa Elisa. Forages were planted mechanically, after the soybean crop harvest on 4/1/2005 and 3/24/2006, in São Gabriel do Oeste, and 3/20/2005 and 3/13/2006, in Dourados. Sorghum, U. brizantha cv. Xaraés and P. maximum cv. Tanzânia characteristics, such as high productivity, high forage quality and easiness in control, were favorable for production of both forage and straw. Urochloa ruziziensis and U. decumbens showed better performance for straw production. Forage cultivation in soybean succession does not affect crop yield.
\end{abstract}

Index terms: Panicum, Urochloa, integrated crop-livestock, pearl millet, cover crop, no tillage.

\section{Introdução}

Baixas temperaturas e estresse hídrico são determinantes para o menor acúmulo de matéria seca das pastagens durante a estação seca. Em condições de pastejo, a demanda por alimento é quase contínua, por isso há grande redução da disponibilidade de forragem nessa estação, caso a suplementação do rebanho com volumoso conservado não tenha sido prevista (Barioni et al., 2003).
A adoção de sistemas de integração lavoura-pecuária é uma forma de suprir parcial ou totalmente o deficit de forragem durante essa estação, com o cultivo de forrageiras anuais tais como aveia, milheto, sorgo forrageiro, ou de espécies perenes dos gêneros Urochloa e Panicum, semeadas em sucessão às culturas de verão.

A adoção do plantio direto tem aumentado a sustentabilidade de atividades agropecuárias, mas os ganhos são limitados pela falta de rotação de culturas 
e de cobertura do solo. De acordo com Bayer et al. (2006), em plantio direto é necessária a entrada de cerca de $4 \mathrm{Mg} \mathrm{ha}^{-1}$ por ano de carbono ao sistema para compensar a quantidade perdida na decomposição dos resíduos orgânicos, o que dificilmente é obtido com culturas anuais. A velocidade com que os restos culturais normalmente são decompostos pode ser facilmente constatada pela falta de cobertura do solo por ocasião do plantio de verão (Bastos Filho et al., 2007) em diferentes regiões do Brasil.

A utilização de pastagens em áreas de lavoura, por períodos de dois anos ou mais, pode contribuir para a melhoria da qualidade física dos solos. Quando nesse sistema ocorre pequeno aumento na densidade do solo - principalmente na camada de $0-15 \mathrm{~cm}$ (Marchão et al., 2007) - uma concentração de raízes na camada superficial pode minimizar o problema. Machado et al. (2007) observaram que, em rotação lavoura-pastagem com média de três anos, havia de 5 a $10 \mathrm{Mg} \mathrm{ha}^{-1}$ de massa seca de raízes de $U$. brizantha, na camada de $0-20 \mathrm{~cm}$ de solo, dependendo do manejo imposto. Santos et al. (2007) e Sarmento et al. (2008) constataram que mais da metade da massa de raízes de espécies de braquiária e de colonião concentra-se na camada de $0-10 \mathrm{~cm}$ do solo.

Os resíduos de matéria seca das pastagens permitem recuperar os teores de matéria orgânica do solo a valores próximos ao original (Freitas et al., 2000; Wendling et al., 2005). Além disso, resíduos vegetais são indispensáveis para aumentar o tamanho e a estabilidade dos agregados, favorecer o controle da erosão e a resistência do solo à compactação.

Outro aspecto importante é que a rotação com pastagem é uma medida eficaz no controle de invasoras (Braz et al., 2006; Correia et al., 2006) e de nematoides reniformes (Asmus, 2005), de cisto da soja e das galhas (Asmus \& Andrade, 2001), além de reduzir a incidência de algumas doenças como o mofo-branco, Fusarium e Rhizoctonia (Toledo-Souza et al., 2008).

Há grande número de artigos sobre o uso de forrageiras anuais dos gêneros Avena, Pennisetum e Sorghum, na entressafra das culturas de verão, porém, estudos com espécies do gênero Urochloa e Panicum para esta finalidade são menos comuns, mesmo sendo o cultivo dessas forrageiras para produção de forragem na estação seca uma prática comum entre os produtores de Mato Grosso do Sul e de outros estados. O aumento da disponibilidade de sementes desses dois gêneros, com consequente redução de preços, tem permitido que essas espécies, apesar de perenes, sejam utilizadas como cultivos de cobertura do solo e forrageiras durante a estação seca.

Torres et al. (2008) observaram que milheto e crotalária superaram $U$. brizantha quanto à produção de fitomassa. Com esse mesmo propósito, Menezes et al. (2009) concluíram que sorgo granífero, capim-pé-de-galinha e $U$. ruziziensis foram as espécies mais promissoras para produção de fitomassa. Em estudo conduzido por Muraishi et al. (2005), as forrageiras do gênero Urochloa apresentaram crescimento inicial mais lento, e foram menos produtivas que espécies anuais, quando avaliadas em curtos intervalos de avaliação (50 dias). Em intervalos mais longos, durante toda a estação seca, Pacheco et al. (2008) observaram que as forrageiras desse gênero são mais produtivas que milheto e híbridos de sorgo forrageiro. Elas também são mais eficientes na supressão de plantas daninhas e resultam em maior produtividade de grãos de soja, quando utilizadas em sistemas de manejo que as empregam em sucessão à cultura de verão (Pacheco et al., 2009).

O objetivo deste trabalho foi avaliar a produção de palha e de forragem por forrageiras anuais e perenes implantadas em sucessão à cultura da soja, e seus efeitos sobre a produtividade de grãos da cultura no próximo cultivo.

\section{Material e Métodos}

Os experimentos foram realizados em dois municípios de Mato Grosso do Sul, durante as estações secas de 2005 e 2006, para avaliação da produção de palha e forragem de oito espécies forrageiras, e na safra de verão 2006/2007, quando foram avaliados os efeitos dessas espécies sobre a produtividade da soja.

Em São Gabriel do Oeste, os experimentos foram conduzidos nas coordenadas $19^{\circ} 24^{\prime} \mathrm{S}$ e $54^{\circ} 34^{\prime} \mathrm{W}$, a $658 \mathrm{~m}$ de altitude, em um Latossolo Vermelho distrófico. Em Dourados, os experinetos foram conduzidos nas coordenadas $22^{\circ} 14^{\prime} \mathrm{S}$ e $54^{\circ} 49^{\prime} \mathrm{W}$, a $408 \mathrm{~m}$ de altitude, em Latossolo Vermelho distroférrico. Em fevereiro de 2005, foram coletadas amostras para análise química do solo (Tabela 1). As precipitações ocorridas no período experimental estão apresentadas na Figura 1.

$\mathrm{O}$ delineamento experimental utilizado foi $\mathrm{o}$ de blocos ao acaso, com parcelas subdivididas e quatro repetições, nos dois locais de avaliação. 
Foram avaliadas as forrageiras Urochloa ruziziensis; $U$. decumbens; U. brizantha cv. Marandu e Xaraés; Panicum maximum cv. Tanzânia e Mombaça, P. maximum x P. infestans cv. Massai; Pennisetum americanum cv. BRS 1501; e Sorghum bicolor cv. Santa Elisa. A cultivar Massai não foi avaliada no segundo ano do experimento em razão de dificuldades operacionais. Durante a estação chuvosa, além dos tratamentos descritos, avaliou-se também a produção de forragem por parcelas em pousio, ocupadas principalmente pelas seguintes espécies: Cenchrus ciliaris, Brachiaria plantaginea, Peschiera fuchsiaefolia e Bidens pilosa.

As parcelas mediam 3,6x10,0 m e foram constituídas por oito linhas de forrageira, espaçadas de $0,40 \mathrm{~m}$. A semeadura foi realizada com semeadeira de parcelas, em 1/4/2005 e 24/3/2006, em São Gabriel do Oeste, e em 20/3/2005 e 13/3/2006, em Dourados. Foram utilizados $4 \mathrm{~kg} \mathrm{ha}^{-1}$ de sementes puras viáveis de $U$. ruziziensis, $U$. decumbens, Panicum maximum cultivares Tanzânia e Mombaça, Panicum maximum x $P$. infestans $\mathrm{cv}$. Massai, $5 \mathrm{~kg} \mathrm{ha}^{-1} \mathrm{de}$ $U$. brizantha cultivares Marandu e Xaraés, e $15 \mathrm{~kg} \mathrm{ha}^{-1}$ de Pennisetum americanum e $S$. bicolor. Em 2005, o valor cultural das sementes comerciais foi de $80 \%$ para $P$. americanum, $90 \%$ para $S$. bicolor e $50 \%$ para as demais espécies. Em 2006, o valor cultural foi igual ao do ano anterior, com excessão de Pannicum maximum cv. Mombaça, que foi de $37 \%$. O experimento semeado em Dourados, em 2005, não emergiu por falta de condições de umidade e temperatura.

Na metade das parcelas, as forrageiras foram avaliadas em regime de cortes sucessivos, quando as plantas atingiam, em média, $60 \mathrm{~cm}$ de altura. Na outra metade, as plantas foram avaliadas após seu crescimento livre. No tratamento com cortes sucessivos, as amostragens foram realizadas com o corte das plantas a $20 \mathrm{~cm}$ acima do solo, nas quatro linhas centrais da parcela, em 6/7/2005, 30/8/2005 e 1/5/2006 (sorgo e milheto), 14/7/2006 e 28/9/2006, em São Gabriel do Oeste e, em Dourados, em 9/5/2006 (sorgo e milheto), 20/7/2006 e 27/9/2006. A última avaliação foi realizada após 21 dias da aplicação de 3,0 $\mathrm{L} \mathrm{ha}^{-1}$ de herbicida glifosato
(360 $\mathrm{g} \mathrm{L}^{-1}$, do equivalente ácido de $\mathrm{N}$-fosfonometil glicina), com o corte das plantas rente ao solo, antes da semeadura da soja, realizada em 17/11/2006, em Dourados, e em 11/11/2005 e 24/11/2006, em São Gabriel do Oeste. Essa última rebrota foi destinada à formação de palhada para o plantio direto da soja.

Por ocasião da semeadura da soja, foi realizada a avaliação da percentagem de controle das forrageiras pelo herbicida. Essa avaliação consistiu na atribuição de notas numa escala de 0 , com todos os perfilhos vivos, a 100, todos mortos, por três avaliadores. Uma aplicação sequencial de 2,0 $\mathrm{L} \mathrm{ha}^{-1}$ foi realizada 21 dias após a primeira aplicação no momento da semeadura da soja. No tratamento com crescimento livre, as forrageiras foram dessecadas no início da estação chuvosa, da mesma forma descrita anteriormente, tendo sido cortadas rente ao solo para estimar a produção de palha.

Em 2005, após a pesagem das massas de matéria fresca de forragem e palha, foram retiradas subamostras de aproximadamente $500 \mathrm{~g}$ para determinação da massa de matéria seca e colocadas em estufa com ventilação forçada, a $61^{\circ} \mathrm{C}$, por 72 horas e, posteriormente, pesadas.

Em 2006, o mesmo procedimento foi adotado para as amostras de forragem e palha. Porém, as subamostras de forragem foram divididas nas frações de colmos e folhas.

As análises dos teores de proteína bruta $\mathrm{e}$ digestibilidade in vitro da matéria orgânica foram realizadas na Embrapa Gado de Corte, em Campo Grande, pela utilização da espectroscopia de reflectância do infravermelho próximo (NIRS).

A cultivar CD 219 RR de soja foi semeada em plantio direto após a aplicação de $2,0 \mathrm{~L} \mathrm{ha}^{-1}$ de glifosato. A semeadeira foi regulada para distribuir $250 \mathrm{~kg} \mathrm{ha}^{-1}$ de fertilizante NPK 0-30-15 e 355.555 sementes viáveis por hectare. As sementes foram tratadas com fungicida Vitavax + Thiram (carboxina + thiram) e, posteriormente, inoculadas com Bradyrhizobium japonicum com veículo turfoso. A colheita mecânica da soja foi realizada em seis linhas de três metros de comprimento, espaçadas de $45 \mathrm{~cm}$, no centro da parcela, em 28/3/2007.

Tabela 1. Resultado da análise de solo antes da implantação dos experimentos em Dourados e São Gabriel do Oeste, MS.

\begin{tabular}{|c|c|c|c|c|c|c|c|c|c|c|c|c|c|c|c|c|}
\hline \multirow[t]{2}{*}{ Localidade } & \multicolumn{2}{|c|}{$\mathrm{pH}$} & $\mathrm{Al}$ & $\mathrm{Ca}$ & $\mathrm{Mg}$ & $(\mathrm{H}+\mathrm{Al})$ & K & $\mathrm{P}$ & SB & CTC & \multirow{2}{*}{$\begin{array}{c}\mathrm{V} \\
(\%)\end{array}$} & \multirow{2}{*}{$\begin{array}{c}\mathrm{MO} \\
\left(\mathrm{g} \mathrm{kg}^{-1}\right)\end{array}$} & $\mathrm{Cu}$ & $\mathrm{Fe}$ & $\mathrm{Mn}$ & \multirow[t]{2}{*}{$\mathrm{Zn}$} \\
\hline & $\mathrm{H}_{2} \mathrm{O}$ & $\mathrm{CaCl}_{2}$ & -- & --- ( & $1_{c} \mathrm{dm}$ & ---------- & ---- & 3)---- & $--(\mathrm{c} 1$ & $\left.\mathrm{dm}^{-3}\right)^{--}$ & & & & & $5)$ & \\
\hline Dourados & 5,2 & 4,4 & 1,0 & 2,8 & 1,3 & 9,9 & 0,63 & 102,3 & 4,73 & 14,7 & 32 & 27,9 & 12,60 & 32,7 & 36,6 & 1,00 \\
\hline S.G.Oeste & 5,6 & 5,1 & 0,0 & 2,6 & 1,3 & 3,1 & 0,19 & 19,0 & 4,04 & 7,1 & 56 & 3,5 & 3,08 & 35,4 & 15,3 & 8,43 \\
\hline
\end{tabular}


Os resultados foram submetidos à análise de variância, e as médias comparadas pelo teste de Tukey, a 5\% de probabilidade, com uso do software Assistat 7.4 Beta (Silva \& Azevedo, 2006).

\section{Resultados e Discussão}

Em 2005, em São Gabriel do Oeste, U. ruziziensis, $U$. decumbens, $U$. brizantha cv. Xaraés, Pennisetum maximum cv. Mombaça e $S$. bicolor foram superiores quanto à produção de forragem em relação a $U$. brizantha cv. Marandu, P. maximum cv. Tanzânia, $P$. maximum $\mathrm{x}$ Pennisetum infestans cv. Massai e Pennisetum americanum (Tabela 2). A cultivar Massai foi a menos produtiva entre as forrageiras avaliadas, sendo que, no primeiro corte, sua produção

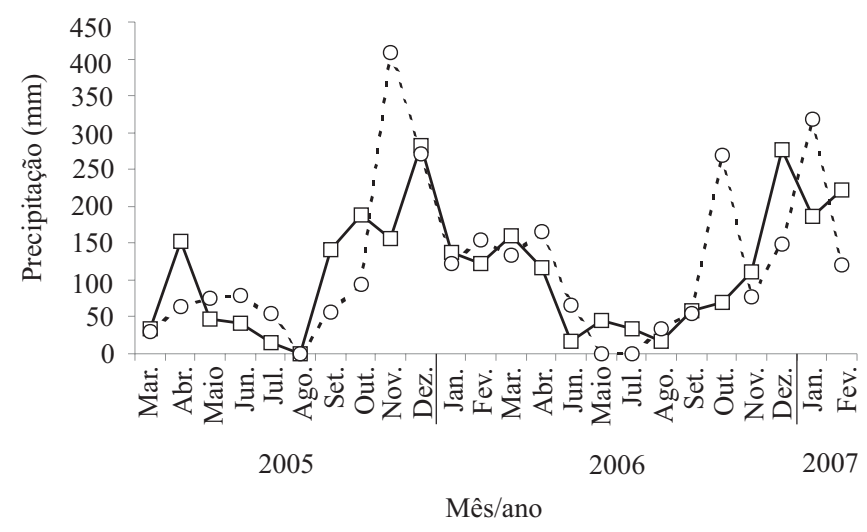

$$
-\square-\text { Dourados --O-- São Gabriel do Oeste }
$$

Figura 1. Precipitações mensais observadas no período de março de 2005 a março de 2007, em Dourados e São Gabriel do Oeste, MS.

Tabela 2. Massa de matéria seca $\left(\mathrm{kg} \mathrm{ha}^{-1}\right)$ de forragem, e de palha após cortes sucessivos ou crescimento livre, em nove forrageiras avaliadas durante a estação seca de 2005 , em São Gabriel do Oeste, $\mathrm{MS}^{(1)}$.

\begin{tabular}{lccc}
\hline Genótipo & Forragem & \multicolumn{2}{c}{ Palha } \\
\cline { 3 - 4 } & & Cortes & Livre \\
\hline Urochloa ruziziensis & $2.555 \mathrm{a}$ & $3.791 \mathrm{a}$ & $4.576 \mathrm{~b}$ \\
Urochloa decumbens & $3.439 \mathrm{a}$ & $4.015 \mathrm{a}$ & $7.095 \mathrm{a}$ \\
Urochloa brizantha cv. Marandu & $1.619 \mathrm{~b}$ & $3.952 \mathrm{a}$ & $3.344 \mathrm{c}$ \\
Urochloa brizantha cv. Xaraés & $2.948 \mathrm{a}$ & $4.332 \mathrm{a}$ & $6.691 \mathrm{a}$ \\
Panicum maximum cv. Tanzânia & $2.250 \mathrm{~b}$ & $4.064 \mathrm{a}$ & $5.551 \mathrm{~b}$ \\
Panicum maximum cv. Mombaça & $3.565 \mathrm{a}$ & $4.446 \mathrm{a}$ & $6.090 \mathrm{a}$ \\
Panicum maximum x Panicum infestans cv. Massai & $969 \mathrm{c}$ & $4.125 \mathrm{a}$ & $5.058 \mathrm{~b}$ \\
Sorghum bicolor & $3.509 \mathrm{a}$ & $2.393 \mathrm{a}$ & $3.267 \mathrm{c}$ \\
Pennisetum americanum & $2.036 \mathrm{~b}$ & - & $2.270 \mathrm{c}$ \\
\hline CV (\%) & 23,8 & 27,3 & 23,6 \\
\hline (1)Médias seguidas de letras iguais na coluna não diferem pelo teste de \\
Tukey, a 5\% de probabilidade.
\end{tabular}

foi praticamente nula. Por sua vez, $P$. americanum apresentou rendimento próximo a zero no último corte, na avaliação realizada em 30/8/2005.

Para produção de palha, as plantas em crescimento livre de $U$. decumbens, $U$. brizantha $\mathrm{cv}$. Xaraés e $P$. maximum cv. Mombaça foram as mais produtivas, enquanto $U$. brizantha cv. Marandu, S. bicolor e $P$. americanum apresentaram a menor produtividade (Tabela 2). O menor rendimento de palha e forragem de $P$. americanum provavelmente está relacionado ao curto ciclo dessa cultura. Ao avaliar quatro cultivares de milheto, Geraldo et al. (2000) obtiveram o pico na taxa de crescimento do milheto entre 51 e 65 dias após o plantio (DAP), com expressiva redução aos 100 DAP.

Embora com metodologia diferente da utilizada neste estudo, Botrel et al. (1999) observaram que $U$. brizantha cv. Marandu foi das espécies mais produtivas durante a estação seca. Os autores relataram que $20 \%$ da produção anual de forragem foi obtida durante a estação seca.

Em 2006, U. brizantha cv. Xaraés e P. maximum cv. Mombaça apresentaram maior produção de forragem que $P$. americanum, quando avaliados em Dourados (Tabela 3). Em São Gabriel do Oeste, S. bicolor foi significativamente mais produtivo que $U$. brizantha cv. Marandu e Xaraés, U. ruziziensis e $U$. decumbens, e não diferiu dos demais genótipos. A maior produção de forragem do S. bicolor em relação a $P$. americanum, quando cultivado em sucessão à soja durante a estação seca, foi relatada por Machado et al. (2004).

O milheto BRS 1501 e o sorgo Santa Elisa, por serem plantas anuais, com sementes maiores e mais vigorosas, se estabeleceram mais rapidamente do

Tabela 3. Massa de matéria seca $\left(\mathrm{kg} \mathrm{ha}^{-1}\right)$ de forragem de oito forrageiras, avaliadas durante a estação seca de 2006, em Dourados e São Gabriel do Oeste, $\mathrm{MS}^{(1)}$.

\begin{tabular}{lcc}
\hline Genótipo & Dourados & São Gabriel do Oeste \\
\hline Urochloa ruziziensis & $926 \mathrm{ab}$ & $1.214 \mathrm{~d}$ \\
Urochloa decumbens & $1.487 \mathrm{ab}$ & $1.884 \mathrm{~cd}$ \\
Urochloa brizantha cv. Marandu & $852 \mathrm{ab}$ & $448 \mathrm{~d}$ \\
Urochloa brizantha cv. Xaraés & $2.540 \mathrm{a}$ & $3.407 \mathrm{bc}$ \\
Panicum maximum cv. Tanzânia & $1.337 \mathrm{ab}$ & $3.565 \mathrm{abc}$ \\
Panicum maximum cv. Mombaça & $2.042 \mathrm{a}$ & $3.754 \mathrm{ab}$ \\
Sorghum bicolor & $1.492 \mathrm{ab}$ & $5.203 \mathrm{a}$ \\
Pennisetum americanum & $153 \mathrm{~b}$ & $3.888 \mathrm{ab}$ \\
\hline CV $(\%)$ & 58,1 & 25,8 \\
\hline
\end{tabular}

${ }^{(1)}$ Médias seguidas de letras iguais na coluna não diferem pelo teste de Tukey, a $5 \%$ de probabilidade. 
que as espécies perenes, e já estariam em condições de serem pastejadas em maio, enquanto as espécies perenes atingiram a condição de pastejo apenas em julho. O milheto encerrou seu ciclo de crescimento em junho, com a maioria de suas plantas já mortas nesta época. Diferenças no acúmulo de massa de matéria seca foram observadas por Timossi et al. (2007), com $P$. glaucum, $B$. decumbens e $B$. brizantha $\mathrm{cv}$. Marandu. Esses autores constataram que, enquanto $P$. glaucum atingiu pico de crescimento ao redor de 100 dias da semeadura, $U$. brizantha somente atingiu essa fase aos 250 dias.

Em Dourados, a produção de folhas de $U$. brizantha cv. Xaraés e de $P$. maximum cv. Mombaça foi significativamente maior que a de $P$. americanum, e não diferiu das demais espécies (Tabela 4). Em São Gabriel do Oeste, a produção de folhas de $U$. ruziziensis, $U$. decumbens e $U$. brizantha $\mathrm{cv}$. Marandu foi significativamente menor do que a das demais espécies avaliadas. Maior rendimento de lâminas foliares foi obtido por Martuscello et al.
(2009) em U. brizantha cv. Xaraés, em relação a outros dois genótipos desse gênero.

$\mathrm{O}$ teor de proteína bruta foi significativamente superior em $U$. ruziziensis e $S$. bicolor, em relação às demais espécies, porém não diferiu de $U$. decumbens, em Dourados, e de U. brizantha cv. Marandu, em São Gabriel do Oeste (Tabela 4). U. ruziziensis apresentou a maior digestibilidade in vitro da matéria orgânica (DIVMO), mas não diferiu significativamente de $U$. decumbens, $U$. brizantha cv. Marandu e Panicum maximum cv. Tanzânia, em Dourados. Em São Gabriel do Oeste, U. ruziziensis apresentou DIVMO superior a todas as espécies avaliadas. Os teores de proteína e digestibilidade in vitro da matéria orgânica das lâminas foliares verificados neste estudo permitiriam bom desempenho de bovinos, se não existissem outros fatores limitantes (National Research Council, 2001). O teor de proteína de $U$. brizantha e $U$. decumbens foi consideravelmente maior do que o observado por Botrel et al. (1999). Essa diferença talvez esteja relacionada à metodologia

Tabela 4. Massa de matéria seca $\left(\mathrm{kg} \mathrm{ha}^{-1}\right)$ de folhas e teor de proteína bruta (\% da matéria seca) e digestibilidade in vitro da matéria orgânica (DIVMO \% da massa de matéria seca), de oito forrageiras avaliadas na estação seca de 2006, em Dourados e São Gabriel do Oeste, MS(1).

\begin{tabular}{|c|c|c|c|c|c|c|}
\hline \multirow[t]{2}{*}{ Genótipo } & \multicolumn{2}{|c|}{ Massa de máteria seca de folhas } & \multicolumn{2}{|c|}{ Proteína bruta } & \multicolumn{2}{|c|}{ DIVMO } \\
\hline & Dourados & S.G.Oeste & Dourados & S.G.Oeste & Dourados & S.G.Oeste \\
\hline Urochloa ruziziensis & $728 \mathrm{ab}$ & $814 b$ & $17,1 \mathrm{a}$ & $16,4 a$ & $77,4 a$ & $82,1 \mathrm{a}$ \\
\hline Urochloa decumbens & $1.108 \mathrm{ab}$ & $1.259 \mathrm{~b}$ & $15,8 \mathrm{ab}$ & $14,2 \mathrm{bc}$ & $73,4 \mathrm{ab}$ & $68,5 \mathrm{c}$ \\
\hline Urochloa brizantha $\mathrm{cv}$. Marandu & $761 \mathrm{ab}$ & $387 b$ & $14,9 \mathrm{bc}$ & $15,1 \mathrm{ab}$ & $74,8 \mathrm{ab}$ & $75,5 b$ \\
\hline Urochloa brizantha cv. Xaraés & $2.162 \mathrm{a}$ & $3.090 \mathrm{a}$ & $12,6 \mathrm{~d}$ & $12,7 \mathrm{c}$ & $64,2 \mathrm{c}$ & $63,1 \mathrm{~cd}$ \\
\hline Panicum maximum cv. Tanzânia & $1.281 \mathrm{ab}$ & $3.183 \mathrm{a}$ & $14,9 b c$ & $14,0 \mathrm{bc}$ & $69,6 a b c$ & $67,5 \mathrm{c}$ \\
\hline Panicum maximum cv. Mombaça & $2.002 \mathrm{a}$ & $3.671 \mathrm{a}$ & $13,7 \mathrm{~cd}$ & $13,3 \mathrm{bc}$ & $68,4 \mathrm{bc}$ & $64,0 \mathrm{~cd}$ \\
\hline Sorghum bicolor & $1.055 \mathrm{ab}$ & $3.000 \mathrm{a}$ & $16,8 \mathrm{a}$ & $16,5 \mathrm{a}$ & $67,9 \mathrm{bc}$ & $60,9 d$ \\
\hline Pennisetum americanum & $86 b$ & $3.064 \mathrm{a}$ & 20,7 & 14,6 & 74,7 & 68,9 \\
\hline $\mathrm{CV}(\%)$ & 56,6 & 27,3 & 4,6 & 6,2 & 5,2 & 3,9 \\
\hline
\end{tabular}

${ }^{(1)}$ Médias seguidas de letras iguais na coluna não diferem pelo teste de Tukey, a 5\% de probabilidade.

Tabela 5. Massa de matéria seca $\left(\mathrm{kg} \mathrm{ha}^{-1}\right)$ de palha dos tratamentos com cortes sucessivos e com crescimento livre das espécies, avaliada após a dessecação das forrageiras nas diferentes localidades, e eficiência do controle (\%) das plantas pelo herbicida e produtividade de grãos de soja $\left(\mathrm{kg} \mathrm{ha}^{-1}\right)$ em São Gabriel do Oeste, MS, na safra 2006/2007 $7^{(1)}$.

\begin{tabular}{|c|c|c|c|c|c|c|}
\hline \multirow[t]{2}{*}{ Genótipo } & \multicolumn{2}{|c|}{ Dourados } & \multicolumn{2}{|c|}{ S.G.Oeste } & \multirow[t]{2}{*}{ Eficiência de controle } & \multirow[t]{2}{*}{ Produtividade de grãos ${ }^{(2)}$} \\
\hline & Cortes & Livre & Cortes & Livre & & \\
\hline Urochloa ruziziensis & $2.633 \mathrm{ab}$ & $4.467 \mathrm{bc}$ & $4.008 \mathrm{ab}$ & $4.929 \mathrm{ab}$ & $99,9 a$ & $1.909 \mathrm{a}$ \\
\hline Urochloa decumbens & $2.905 \mathrm{ab}$ & $5.546 \mathrm{bc}$ & $4.324 \mathrm{ab}$ & $5.992 \mathrm{a}$ & $99,3 \mathrm{ab}$ & $2.054 \mathrm{a}$ \\
\hline Urochloa brizantha cv. Marandu & $3.763 \mathrm{a}$ & $4.395 \mathrm{bcd}$ & $4.025 \mathrm{ab}$ & $6.805 \mathrm{a}$ & $96,2 \mathrm{ab}$ & $2.159 \mathrm{a}$ \\
\hline Urochloa brizantha cv. Xaraés & $3.687 \mathrm{a}$ & $9.437 \mathrm{a}$ & $5.196 \mathrm{a}$ & $7.232 \mathrm{a}$ & $96,2 \mathrm{ab}$ & $2.008 \mathrm{a}$ \\
\hline Panicum maximum cv. Tanzânia & $2.997 \mathrm{ab}$ & $5.766 \mathrm{abc}$ & $4.319 \mathrm{ab}$ & $5.731 \mathrm{a}$ & $82,3 \mathrm{bc}$ & $1.943 \mathrm{a}$ \\
\hline Panicum maximum cv. Mombaça & $4.026 \mathrm{a}$ & $7.454 \mathrm{ab}$ & $4.584 \mathrm{ab}$ & $7.091 \mathrm{a}$ & $73,0 \mathrm{c}$ & $1.978 \mathrm{a}$ \\
\hline Sorghum bicolor & $1.311 b c$ & $2.104 \mathrm{~cd}$ & $3.854 \mathrm{ab}$ & $4.981 \mathrm{ab}$ & $99,1 \mathrm{ab}$ & $2.172 \mathrm{a}$ \\
\hline Pennisetum americanum & $285 c$ & $656 \mathrm{~d}$ & $3.047 \mathrm{bc}$ & $2.315 b$ & $100,0 \mathrm{a}$ & $2.150 \mathrm{a}$ \\
\hline Pousio & - & $485 c$ & - & $1.595 \mathrm{c}$ & $100 \mathrm{a}$ & $2.049 \mathrm{a}$ \\
\hline CV (\%) & 29,6 & 32,2 & 22,0 & 23,7 & 7,6 & 8,6 \\
\hline
\end{tabular}

${ }^{(1)}$ Médias seguidas de letras iguais na coluna não diferem pelo teste de Tukey, a 5\% de probabilidade. ${ }^{(2)}$ Valores ajustados para $13 \%$ de umidade. 
empregada nos dois estudos, pois, enquanto neste trabalho as forrageiras foram avaliadas por um curto período de tempo, Botrel et al. (1999) realizaram determinações durante todo o ano.

Em Dourados, as cultivares de $U$. brizantha e o $P$. maximum $\mathrm{cv}$. Mombaça foram mais produtivas que S. bicolor, Pennisetum americanum e ao pousio, e não diferiram significativamente dos demais tratamentos (Tabela 5). Em São Gabriel do Oeste, U. brizantha cv. Xaraés foi significativamente mais produtiva que P. americanum e ao pousio, e não diferiu dos demais tratamentos. Após 21 dias da aplicação do herbicida glifosato, $U$. ruziziensis, $S$. bicolor e $P$. americanum apresentaram maior percentagem de controle pelo herbicida que as cultivares Tanzânia e Mombaça de P. maximum. Timossi et al. (2007) observaram maior percentual de controle de $U$. decumbens em relação a $U$. brizantha aos 14, 21 e 28 dias da aplicação de $1,44 \mathrm{~kg} \mathrm{ha}^{-1}$ do herbicida glifosato.

A produtividade de grãos da cultura da soja não apresentou diferença significativa em relação às forrageiras que a antecederam (Tabela 5). As variações ocasionadas pelas diferentes coberturas podem ter sido menores que a de outros fatores relacionados ao solo, à semeadura e à avaliação do experimento. Em vários estudos, as vantagens das forrageiras como plantas de cobertura são demonstradas, no que diz respeito à química e à física do solo e à variáveis de ordem sanitária. Porém, esses benefícios parecem não se refletir na produtividade de grãos (Guimarães et al., 2003; Carvalho et al, 2004; Muraishi et al., 2005). O período de avaliação de experimentos desta natureza deve ser mais longo para que os efeitos do sistema de produção possam ser medidos de maneira mais apropriada.

A forrageira $U$. brizantha cv. Xaraés apresentou maior rendimento de palha, com plantas em crescimento livre, não submetidas ao corte, em relação aos demais tratamentos, exceto a $P$. maximum cv. Tanzânia e Mombaça, em Dourados (Tabela 5). Em São Gabriel do Oeste, Pennisetum americanum foi significativamente inferior aos demais tratamentos, exceto a $U$. ruziziensis e $S$. bicolor. Estes resultados estão de acordo com os obtidos por Timossi et al. (2007), em que B. brizantha e $B$. decumbens apresentaram maior rendimento que milheto. Esses autores observaram que o milheto apresentou boa cobertura num ciclo curto de desenvolvimento, mas não evitou o surgimento de plantas daninhas. Pacheco et al. (2008) observaram que $B$. decumbens, B. ruziziensis, B. brizantha e sorgo forrageiro foram mais produtivas que milheto e capim-pé-de-galinha, em sobressemeadura na cultura da soja. Estes resultados diferem dos obtidos por Torres et al. (2008), que avaliaram coberturas por um período mais curto, e constataram que o milheto foi mais produtivo que $B$. brizantha, que não pôde demonstrar todo o potencial esperado no final da estação seca. Muraishi et al. (2005) obtiveram maior rendimento do milheto em relação a duas espécies do gênero Brachiaria. Porém, o período entre a semeadura das forrageiras e a da soja foi curto (90 dias).

$\mathrm{Na}$ entressafra das culturas de verão, as forrageiras em pastejo contribuem em diferentes momentos. As espécies anuais, milheto e sorgo, podem suprir a demanda de forragem no início da estação seca, em abril e maio. Já as espécies perenes podem atender à necessidade de forragem durante a estação seca, de junho até o final de setembro, quando é necessário interromper o acesso dos animais às pastagens para formação de matéria para dessecação.

Estudos sobre avaliação do desempenho zootécnico de bovinos e de outros ruminantes são fundamentais para que resultados conclusivos acerca do potencial de uso dessas forrageiras em sucessão às culturas de verão sejam obtidos.

\section{Conclusões}

1. As espécies $S$. bicolor cv. Santa Elisa, Uruchloa brizantha cv. Xaraés e Panicum maximum cv. Tanzânia apresentam características favoráveis à produção de forragem e palha na entressafra das culturas de verão, em razão do elevado rendimento de massa de matéria seca, qualidade bromatológica e facilidade de controle.

2. As forrageiras Uruchloa ruziziensis e Uruchloa decumbens, por manterem-se em crescimento durante toda a estação seca e pela facilidade de dessecação, podem ser mais bem aproveitadas com o propósito de cobertura do solo.

\section{Referências}

ASMUS, G.L. Reação de algumas culturas de cobertura utilizadas no sistema plantio direto ao nematóide reniforme. Dourados: Embrapa Agropecuária Oeste, 2005. 4p. (Embrapa Agropecuária Oeste. Comunicado técnico, 99). 
ASMUS, G.L.; ANDRADE, P.J.M. Reprodução do nematóide das galhas (Meloidogyne javanica) em algumas plantas alternativas para uso em sucessão à cultura da soja. Dourados: Embrapa Agropecuária Oeste, 2001. 4p. (Embrapa Agropecuária Oeste. Comunicado técnico, 37).

BARIONI, L.G.; MARTHA JÚNIOR, G.B.; RAMOS, A.K.B.; VELOSO, R.F.; RODRIGUES, D. de C.; VILELA, L. Planejamento e gestão do uso de recursos forrageiros na produção de bovinos em pastejo. In: SIMPÓSIO SOBRE MANEJO DA PASTAGEM, 20., 2003, Piracicaba. Produção animal em pastagens: situação atual e perspectivas: anais. Piracicaba: FEALQ, 2003. p.105-154.

BASTOS FILHO, G.; NAKAZONE, D.; BRUGGEMANN, G.; MELO, H. Rally da safra 2007: uma avaliação do plantio direto no Brasil. Revista Plantio Direto, n.101, 2007. Disponível em: $<$ http://www.plantiodireto.com.br/?body=cont_int\&id=823 $>$. Acesso em: 7 abr. 2010.

BAYER, C.; LOVATO, T.; DIECKOW, J.; ZANATTA, J.A.; MIELNICZUK, J. A method for estimating coefficients of soil organic matter dynamics based on long-term experiments. Soil Tillage Research, v.19, p.217-226, 2006.

BOTREL, M. de A.; ALVIM, M.J.; XAVIER, D.F. Avaliação de gramíneas forrageiras na região Sul de Minas Gerais. Pesquisa Agropecuária Brasileira, v.34, p.683-689, 1999.

BRAZ, A.J.B.P.; PROCÓPIO, S.O.; CARGNELUTTI FILHO, A.; SILVEIRA, P.M.; KLIEMANN, H.J.; COBUCCI, T.; BRAZ, G.B.P. Emergência de plantas daninhas em lavouras de feijão e de trigo após o cultivo de espécies de cobertura de solo. Planta Daninha, v.24, p.621-628, 2006.

CARVALHO, M.A.C. de; ATHAYDE, M.L.F.; SORATTO, R.P.; ALVES, M.C.; ARF, O. Soja em sucessão a adubos verdes no sistema de plantio direto e convencional em solo de Cerrado. Pesquisa Agropecuária Brasileira, v.39, p.1141-1148, 2004.

CORREIA, N.M.; DURIGAN, J.C.; KLINK, U.P. Influência do tipo e da quantidade de resíduos vegetais na emergência de plantas daninhas. Planta Daninha, v.24, p.245-253, 2006.

FREITAS, P.L. de; BLANCANEAUX, P.; GAVINELLI, E.; LARRÉ-LARROUY, M.C.; FELLER, C. Nível e natureza do estoque orgânico de latossolos sob diferentes sistemas de uso e manejo. Pesquisa Agropecuária Brasileira, v.35, p.157-170, 2000 .

GERALDO, J.; ROSSIELLO, R.O.P.; ARAÚJO, A.P.; PIMENTEL, C. Diferenças em crescimento e produção de grãos entre quatro cultivares de milheto pérola. Pesquisa Agropecuária Brasileira, v.35, p.1367-1376, 2000.

GUIMARÃES, G.L.; BUZETTI, S.; SILVA, E.C. da; LAZARINI, E.; SÁ, M.E. de. Culturas de inverno e pousio na sucessão da cultura da soja em plantio direto. Acta Scientiarum. Agronomy, v.25, p.339-344, 2003.

MACHADO, L.A.Z.; ASSIS, P.G.G. de; PALOMBO, C. Sorgo para pastejo/corte e cobertura do solo no período outono/ inverno (safrinha) em Mato Grosso do Sul. Dourados: Embrapa Agropecuária Oeste, 2004. 19p. (Embrapa Agropecuária Oeste. Boletim de pesquisa e desenvolvimento, 16).
MACHADO, L.A.Z.; FABRÍCIO, A.C.; ASSIS, P.G.G. de; MARASCHIN, G.E. Estrutura do dossel em pastagens de capim-Marandu submetidas a quatro ofertas de lâminas foliares. Pesquisa Agropecuária Brasileira, v.42, p.1495-1501, 2007.

MARCHÃO, R.L.; BALBINO, L.C.; SILVA, E.M. da; SANTOS JUNIOR, J. de D.G. dos; SÁ, M.A.C. de; VILELA, L.; BECQUER, T. Qualidade física de um Latossolo Vermelho sob sistemas de integração lavoura-pecuária no Cerrado. Pesquisa Agropecuária Brasileira, v.42, p.873-882, 2007.

MARTUSCELLO, J.A.; JANK, L.; GONTIJO NETO, M.M.; LAURA, V.A.; CUNHA, D. de N.F.V. da. Produção de gramíneas do gênero Brachiaria sob níveis de sombreamento. Revista Brasileira de Zootecnia, v.38, p.1183-1190, 2009.

MENEZES, L.A.S.; LEANDRO, W.M.; OLIVEIRA JÚNIOR, J.P. de; FERREIRA, A.C. de B.; SANTANA, J. das G.; BARROS, R.G. Produção de fitomassa de diferentes espécies, isoladas e consorciadas, com potencial de utilização para cobertura dos solo. Bioscience Journal, v.25, p.7-12, 2009.

MURAISHI, C.T.; LEAL, A.J.F.; LAZARINI, E.; RODRIGUES, L.R.; GOMES JUNIOR, F. G. Manejo de espécies vegetais de cobertura do solo e produtividade do milho e da soja em semeadura direta. Acta Scientiarum. Agronomy, v.27, p.199-207, 2005.

NATIONAL RESEARCH COUNCIL. Nutrient requirements of dairy cattle. $7^{\text {th }}$ ed. Washington: National Academy Press, 2001. $381 \mathrm{p}$.

PACHECO, L.P.; PIRES, F.R.; MONTEIRO, F.P.; PROCÓPIO, S. de O.; ASSIS, R.L. de; CARGNELUTTI FILHO, A.; CARMO, M.L. do; PETTER, F.A. Sobressemeadura da soja como técnica para supressão da emergência de plantas daninhas. Planta Daninha, v.27, p.455-463, 2009

PACHECO, L.P.; PIRES, F.R.; MONTEIRO, F.P.; PROCÓPIO, S. de O.; ASSIS, R.L. de; CARMO, M.L. do.; PETTER, F.A. Desempenho de plantas de cobertura em sobressemeadura na cultura da soja. Pesquisa Agropecuária Brasileira, v.43, p.815-823, 2008.

SANTOS, R.S.M. dos; OLIVEIRA, I.P. de; MORAIS, R.F. de; URQUIAGA, S.C.; BODDEY, R.M.; ALVES, B.J.R. Componentes da parte aérea e raízes de pastagens de Brachiaria spp. em diferentes idades após a reforma, como indicadores de produtividade em ambiente de Cerrado. Pesquisa Agropecuária Tropical, v.2, p.119-124, 2007.

SARMENTO, P.; RODRIGUES, L.R. de A.; LUGÃO, S.M.B.; CRUZ, M.C.P. da; CAMPOS, F.P. de; FERREIRA, M.E.; OLIVEIRA, R.F. de. Sistema radicular do Panicum maximum Jacq. cv. IPR-86 Milênio adubado com nitrogênio e submetido à lotação rotacionada. Revista Brasileira de Zootecnia, v.37, p.27-34, 2008.

SILVA, F. de A.S. e.; AZEVEDO, C.A.V. de. A new version of the Assistat-Statistical Assistance Software. In: WORLD CONGRESS ON COMPUTERS IN AGRICUlTURE, 4., Orlando. Anais. Orlando: American Society of Agricultural and Biological Engineers, 2006. p.393-396. 
TIMOSSI, P.C.; DURIGAN, J.C.; LEITE, G.J. Formação de palhada por braquiárias para adoção do Sistema Plantio Direto. Bragantia, v.66, p.617-622, 2007.

TOLEDO-SOUZA, E.D. de; SILVEIRA, P.M. da; LOBO JUNIOR, M.; CAFÉ FILHO, S.C. Sistemas de cultivo, sucessões de culturas, densidade do solo e sobrevivência de patógenos de solo. Pesquisa Agropecuária Brasileira, v.43, p.971-978, 2008.
TORRES, J.L.R.; PEREIRA, M.G.; FABIAN, A.J. Produção de fitomassa por plantas de cobertura e mineralização de seus resíduos em plantio direto. Pesquisa Agropecuária Brasileira, v.43, p.421-428, 2008.

WENDLING, B.; JUCKSCH, I.; MENDONÇA, E. de S.; NEVES, J.C.L. Carbono orgânico e estabilidade de agregados de um Latossolo Vermelho sob diferentes manejos. Pesquisa Agropecuária Brasileira, v.40, p.487-494, 2005.

Recebido em 7 de agosto de 2009 e aprovado em 26 de fevereiro de 2010 